\title{
Cutaneous Malignant Melanoma
}

\author{
Kutanöz Malign Melanom
}

\author{
Nilay DUMAN \\ Afyon Kocatepe Üniversitesi, Tıp Fakültesi, Dermatoloji Ana Bilim Dalı, Afyonkarahisar
}

Dergiye ulaşma tarihi: 14/08/2014, Dergiye kabul tarihi:28/08/2014 Doi: 10.5505/aot.2014.27247

\section{ÖZET}

Tüm dünyada insidansı giderek artan kutanöz malign melanom derinin en ölümcül kanseridir. Burada kutanöz malign melanom ele alınmış ve epidemiyolojik özellikleri, risk faktörleri, klinik ve histopatolojik özellikleri, evreleme, tedavi ve takip modaliteleri derlenmiştir. Böylelikle kutanöz malign melanom hastasına klinik yaklaşımda kolaylık oluşturulması amaçlanmıştır.

Anahtar Kelimeler: Melanom; Risk faktörleri; Evreleme; Tedavi

\begin{abstract}
The incidence of cutaneous malignant melanoma which is the most lethal skin cancer, is increasing all over the world.. Herein, cutaneous malignant melanoma is reviewed with its epidemiological features, risk factors, clinical and histopathological features, staging, treatment and follow-up modalities.. Thus, it is aimed to create ease of clinical approach for cutaneous malignant melanoma patients.
\end{abstract}

Key words: Melanoma; Risk factors; Staging; Treatment

\section{Epidemiyoloji}

Kutanöz malign melanom (MM), melanositlerden köken alan malign deri tümörüdür. En ölümcül deri kanseri olması nedeniyle ayrı bir öneme sahiptir. Tüm deri kanserlerinin \%4'ü MM olmasına rağmen, deri kanserlerine bağlı ölümlerin \%80-85'ini MM oluşturur (1).

Global olarak yılda yaklaşık 160.000 yeni MM olgusu ve buna bağl1 48.000 ölüm ortaya çıkmaktadır (2). MM insidansı etnik gruplar ve anatomik bölgelere göre farklllık göstermektedir. Tüm dünya da en yüksek MM insidans1 Queensland, Avustralya ve Yeni Zelenda'da görülmektedir (2). MM insidans1, koyu tenli 1rklarda (Afrikalı, Yerli Amerikan, Asyalı ve İspanyol) beyaz 1rka göre daha düşüktür (3). Beyaz ırktaki yıllık insidans artış1 \%2-7 arasında bildirilmiştir (4).

MM insidansı genel olarak kadın ve erkek arasında benzerdir. Ancak 40 yaş altında, genç kadınlarda daha yüksekken, 40 yaş sonrası, erkeklerde daha hızlı bir insidans artışı gözlenmektedir (5). Gövde ve alt ekstremite yerleşimli MM insidansında baş-boyun yerleşimli MM'ye kıyasla daha hızlı bir artış görülmüştür (6).

\section{Etyopatogenez ve Risk Faktörleri}

MM genetik duyarlılık ve çevresel faktörlerin etkileşimi sonucu ortaya çıkan multifaktöriyel bir kanserdir (7). MM ailelerinin yaklaşık 1/3'ünde 9p21 lokusundaki siklin bağımlı kinaz inhibitör 2A (CDKN2A) geninde mutasyon gösterilmiştir (2). CDKN2A geni, $\mathrm{p} 16^{\mathrm{INK} 4 \mathrm{~A}}$ ve $\mathrm{p} 14^{\mathrm{ARF}}$ proteinlerini sentezler, tümör supresyon geni olarak hücre siklus regülasyonunda görev alır. CDKN2A gen ürünleri p16 ve p14 hücre siklusu üzerindeki regülatuvar etkilerini retinoblastom $(\mathrm{Rb})$ proteini ve p53 yolakları üzerinden yaparlar $(8,9)$.

MM gelişiminde bir diğer önemli yolak NRAS/MAPK (mitojen aktive protein kinaz) yolağıdır. Sporadik MM'lerin çoğunda tespit edilen RAS ve BRAF mutasyonları bu yolağın sürekli aktivasyonuna sebep olmaktadır. NRAS, RAS ailesine ait bir protoonkogendir. Primer ve metastatik MM'lerin yaklaşık 1/3'ünde NRAS mutasyonları gösterilmiştir ve bu mutasyon artmış metastaz ve kötü prognozla ilişkili bulunmuştur (10). RAF ise RAS inhibitörü olarak görev yapar, RAS ve MAPK yolağında kritik bir bağlantı noktasıdır. RAF'1n 3 izoformu mevcuttur. BRAF izofor- 
mundaki mutasyonlar sporadik MM'lerin \%5060'ında gösterilmiştir ve bu mutasyon genellikle çok sayıda nevüs varlığı, genç yaş (20-30 yaş), gövde, ekstremite yerleşimi ve yüzeyel yayılan MM ile ilişsilendirilmiştir (2, 8,10-12). Son y1llarda metastatik MM tedavisinde BRAF yolağını hedefleyen tedaviler (vemurafenib, dabrafenib) ön plana çıkmıştır $(2,10)$.

MM gelişiminde rol oynayan diğer bir yolak da PI3K/AKT (fosfotidilinositol fosfat kinaz-aktive protein kinaz B) yolağıdır. PTEN tümör supresör geni bu yolakta önemli regülatuvar fonksiyona sahiptir $(1,10)$. MM hücrelerinin \%30-40'inda homozigot PTEN delesyonları saptanmıştır (10). PTEN delesyonları PI3K/AKT yolağını aktive ederek, benign melanosit proliferasyonundan invaziv MM gelişmesine neden olmaktadır (10).

Kseroderma pigmentozum, okulokutanöz albinizm gibi bazı genetik sendromlarda ve BRCA2 mutasyonu taşıyan meme-over kanser ailelerinde $\mathrm{MM}$ riskinin arttı̆ 1 bilinmektedir $(8,13)$.

Güneş maruziyeti, MM gelişimi içim en önemli çevresel faktördür. MM karsinogenez basamaklarında, UV'ye bağlı DNA hasarına ikincil oluşmuş mutasyonlar primer rolü oynar. Son y1llarda UV'nin CDKN2A, PTEN, NRAS ve BRAF gibi MM ilişkili genlerde de mutasyon oluşturduğu gösterilmiştir (14). Yoğun aralıklı güneş maruziyeti yüzeyel yayılan MM gelişimini ve ayrıca kişinin multiple primer $\mathrm{MM}$ geliştirme riskini de arttırmaktadır. Kronik sürekli paternde güneş maruziyeti özellikle lentigo MM riskinde artışa yol açmaktadır. Güneş yanığı öyküsü yoğun intermitan UV maruziyeti belirteci olabilmesi açısından önemlidir. Çocuklukta güneş yanığı varlığı MM riskini 2 kat arttırırken, erişkinlikteki yanık MM riskinde yaklaşık 1.53 kat artışa yol açmaktadır (7).

Solaryum, fototerapi gibi artifisyel UV maruziyeti de MM riskinde artışa yol açmaktadır. On dokuz çalışmanın dahil edildiği bir meta analizde solaryumun MM riskini yaklaşık 1.15 kat arttırdığı gösterilmiştir, 35 yaş altında alınan solaryum ise riski 1.75 kat arttırmaktadır (15). Ayrıca, 250 seans üzerinde psoralenli UVA (PUVA) tedavisi alan psoriyazis hastalarında MM riskinde 5 kat artış olduğu, bu riskinde tedaviden 15 y1l sonra ortaya çıktığı gösterilmiştir (16). Bu hastalarda MM'nin uzun bir latent dönem sonras1 gelişebildiği, 25 y1llık takipte bu riskin 10 kat arttı̆̆ gösterilmiştir (17).

Kızıl, sarı saç, açık renk ten, çillerin varlığ 1 , açık renk göz ve deri fototipi I gibi fenotipik özellikler MM riskini arttırmaktadır. Kızıl saç varlığında en yüksek risk artış1 (rölatif risk: 3.64) mevcuttur. Özellikle sirt bölgesinde artmış çillenme gösteren kişilerde risk 2 kat artmaktadır. Fitzpatrick deri fototipi I'e sahip bireylerde fototip IV'e göre iki kat artış mevcuttur (18). Açık renk göz (mavi, yeşil) kişinin MM riskini \%50 arttırmaktadır (7).

Kişisel MM öyküsü varlığı olan kişilerde ikincil MM riski artmaktadır. Dörtbindörtyüzseksendört hastanın dahil edildiği prospektif bir çalışmada 5 yıl içinde ikincil MM gelişme riskinin \%11 olduğu ve bunun çoğunluğunun da ilk bir y1l içinde geliştiği gösterilmiştir. Aile öyküsü de olan hastalarda bu risk \%19'a yükselmektedir $(7,19)$. Ek olarak displastik nevüsün varlığ 1 ikincil MM riskini 2-3 kat arttırmaktadır $(7,19)$. Ailede MM öyküsü de MM riskini arttırmaktadır. Ailede birinci derece yakınında MM öyküsü MM riskini 1.7 kat arttırırken, iki tane MM'li yakın varlığında ise bu risk 9 kat artmaktadır (20).

Kişisel MM dışı deri kanseri öyküsü varlığında MM riski artmaktadır. Bazal hücreli karsinom (BHK) ve skuamöz hücreli karsinom (SHK) gelişiminde UV maruziyeti temel rolü oynadığı için MM riskinin de artmış olduğu bilinmektedir. Monghoob ve ark., BHK ve/veya SHK'lı hastalarda MM gelişme riskinin 17 kat arttı̆̆ını göstermişlerdir (21). Daha geniş bir meta analizde ise rölatif risk 4.28 olarak belirlenmiştir (18). MM riskinin arttığ diğer bir deri kanseri ise mikozis fungoidestir (MF). İki yüz elli MF'li hasta ile yapılan bir çalışmada MM riskinin 15 kat arttığ1 gösterilmiştir, bunun da immünsupresyonla ilişkili olduğu düşünülmüştür (22).

Elli yaş üzerinde erkeklerde MM riski artmıştır. Ayrıca yaşlı erkeklerdeki MM'lerin daha hızlı büyüme gösterdikleri, daha kalın ve genelde nodüler tipte oldukları gösterilmiştir $(23,24)$.

Çok sayıda melanositik nevüs varlı̆g 1 MM riskini arttırmaktadır. Total melanositik nevüs sayısı MM riski ile pozitif koreledir (7). Gandini ve ark., yaptıkları meta analizde 100 'den fazla nevüs varlığının MM riskinde 7 kat artışla ilişkili olduğunu göstermiştir (25). 
Displastik nevüs varlığı MM riskini arttırmaktadır. Gandini ve ark., bir displastik nevüs varlığında bile sporadik MM riskinin artmış olduğunu, sayısı 5 ise bu riskin 6 kat arttığını göstermişlerdir (25). Ailelerinde MM öyküsü bulunan ve özellikle de bu öykü ikiden fazla birinci derece yakınında olan displastik nevüs hastalarında MM riski en yüksektir (19). MM riski her tip konjenital melanositik nevüs varlığında artsa da en büyük artış $20 \mathrm{~cm}$ üstü dev konjenital melanositik nevüslerde izlenir. $\mathrm{Bu}$ hastalarda hayat boyu $\mathrm{MM}$ gelişme riski $\% 10$ 'dan küçükse de rölatif risk yüksektir, çeşitli çalışmalarda 52-465 arasında bildirilmiştir (7).

Kronik immünsupresyon varllğında MM riski artmaktadır. Kanser ve akkiz immün yetmezlik sendromuna (AIDS) bağl1 immünsupresyonun $\mathrm{MM}$ riskini arttırdığ1, ayrıca kronik lenfositik lösemili ya da nonhodgkin lenfomalı hastalarda tedaviden bağımsı MM riskinin arttığı bilinmektedir (26-28). Organ transplantasyonu sonras1 da MM gelişme riski artmaktadır, erişkinlerde postransplant deri kanserlerinin \%6'sin1, çocuklarda \%15'ini MM oluşturur $(29,30)$.

\section{Klinik özellikler}

MM geleneksel olarak klinik ve patolojik özelliklerine bağlı olarak 4 alt tipe; yüzeyel yayılan MM, nodüler MM, lentigo $\mathrm{MM}$ ve akral lentijinöz MM ayrılmıştır (31).

Yüzeyel yayılan MM, açık tenli bireylerde en s1k görülen MM alt tipidir, tüm MM'lerin \%70'ini oluşturur. Siklıkla 30-50 yaş arasında görülür. En sık intermitan güneş gören bölgelerde, erkeklerde gövdede ve kadınlarda bacaklarda yerleşir. Yüzeyel yayılan MM, denovo çıkabileceği gibi nevüs üzerinden de gelişebilir. Nevüsle ilişkili MM'lerin çoğu bu tiptedir (31). Yüzeyel yayılan MM'de tipik klinik öykü 1-5 yıl içinde yavaş değişiklik gösteren kahve-siyah lezyon varlığ 1 ile karakterizedir. İlk önce asimetrik, renk çeşitliliği ve sınır düzensizliği olan makül veya yama şeklinde başlar, daha sonra lezyon üzerinde papül veya nodül gelişimi görülür. Lezyonların yaklaşı 2/3'ünde gri, hipodepigmente alanlar olarak görülen regresyon alanları izlenir (31).

Nodüler MM, açık tenli bireylerde ikinci sıklıkta görülen $\mathrm{MM}$ alt tipidir, tüm MM'lerin \%15-30'unu oluşturur. Siklıkla altıncı dekatta, gövde, baş-boyun bölgelerinde ortaya çıkar. Erkeklerde kadınlardan daha sıktır. Genellikle mavi-siyah, bazen pembekırmızı ülsere olabilen nodüller şeklinde hızlı bir şekilde ortaya çıkar (31).

Lentigo MM, tüm kutanöz MM'lerin $\% 15$ 'den azını oluşturur. Genellikle daha ileri yaşlarda, yedinci dekatta, kronik sürekli UV maruziyetinin olduğu yüz özellikle de burun ve yanaklarda ortaya çıkar. Yavaş büyüyen, asimetrik, renk çeşitliliği gösteren irregüler sinırlı kahve-siyah renkli yama şeklinde başlar. Lentigo maligna adı verilen in-situ fazdan invazyon gelişimi sonucu ortaya çıkar (31).

Akral lentijinöz MM, kutanöz MM'lerin \%5-10'ununu oluşturur. İnsidans1 etnik farklılıklardan en çok etkilenen, siyah 1rkta (\%70) ve Asyalılarda (\%45) en sik görülen MM alt tipidir. UV maruziyeti ile ilişkisizdir, sıklıkla avuç içinde, ayak tabanında ve tırnakta kahve-siyah irregüler lezyonlar şeklinde ortaya çıkar (31).

$\mathrm{Bu}$ klasik alt tiplerin dışında MM'lerin klinikopatolojik varyantları arasında amelanotik, nevoid, hayvan tipi, dezmoplastik/ nörotropik MM, çocukluk çağı MM, persistan, rabdoid, miksoid, metaplastik, adenoid, anyiotropik, taşlı yüzük hücreli, balon hücreli, berrak hücreli, nöroendokrin diferansiyasyon gösteren MM gibi farklı alt tipler de yer alır, bunların ayırımı daha çok histopatolojik özelliklere göre yapılabilir (31-33).

\section{Histopatolojik Özellikler ve İdeal Histopatolojik Raporlama}

MM tanısında, histopatolojik değerlendirme altın standarttır. Histopatolojik tanısı; yapısal ve sitolojik özelliklerin birlikte değerlendirilmesi ile konur. Genel histopatolojik özellikleri arasında lezyonda asimetri, diffüz sitolojik atipi varlığı, melanom hücrelerinin epidermiste lentijinöz ve pagetoid yayılım göstermesi ve dermiste yuvalar yerine büyük kümeler ve nodüller oluşturması, dermal mitoz ve anormal mitoz varlığ 1 ve matürasyon kaybı olarak sayılabilir (31-33). Ayrıca MM'lerin histopatolojik incelemesinde ülserasyon, tümörü infiltre eden lenfohistiyositik infiltrasyon, pigment inkontinas1, melanofajlar, regresyon bulguları, mikroskopik satellit ve intransit metastazlar, lenfovasküler ve perinöral invazyon gibi ek bulgulara da sıklıkla rastlanmaktadır (31-33). 
MM'de histopatolojik parametreler tedavi yaklaşımlarını ve prognozu belirleyici olduğu için mutlaka ayrıntılı değerlendirilmelidir $(34,35)$. İyi bir histopatolojik raporda makroskopik özellikler (lokalizasyon, boyut, pigmentasyonun özellikleri ve makroskopik satellit varlı̆̆g) ve mikroskopik özellikler (MM alt tipi, prekürsör nevüs varlığı, büyüme fazı, Breslow kalınlığı, Clark seviyesi, ülserasyon varllğg-boyutu, mitotik indeks, tümörü infiltre eden lenfohistiyositik infiltrat ve yoğunluğu, tümör regresyonu ve oranı, lenfovasküler ve perinöral invazyon, mikrosatellit varlı̆̆ 1 , cerrahi sınır durumu ve boyutu), lenf nodları çıkarıldıysa sentinel ve/veya total lenf nodu sayısı, sentinel lenf nodu (SLN) için ekstranodal yayılım varlığı, en büyük metastatik odağın boyutu ve metastatik tümörün yerleşimi (subkapsüler ve/veya intramedüller) ayrıntılı yer almalıdır (34).

\section{Klinik ve Patolojik Evrelendirme}

MM klinik ve patolojik evrelendirmesinde en son kullanilan evreleme sistemi Amerikan Birleşik Kanser Komitesi (AJCC)'nin 2009 yılında yayınladığı TNM (Tümör-nodmetastaz) evreleme sistemidir (36). Bu evreleme sisteminde tümörün özellikleri (Breslow kalınlığı, ülserasyon varlığ 1 , mitotik oran), lenf nodlarının durumu, uzak metastaz varlığ1 ve serum laktat dehidrogenaz (LDH) düzeyi dikkate alınır. Evreleme için öncelikle ayrıntılı fizik muayene ve klinik sorgulama ile lenf nodlarının durumu ve uzak metastaz varlığına ait semptom ve bulgular değerlendirilmelidir. Uygun hasta gruplarında lenf nodu tutulumu ve uzak metastaz varlığına yönelik et tetkikler istenmelidir (36).

SLN inceleme, lenfatik yayılım riski en yüksek olan bölgesel lenf nodunun incelenmesini sağlayan ve radikal lenf nodu cerrahilerini azaltan bir yöntemdir. MM'li hastalarda SLN inceleme kullanılabilirliği büyük ölçüde kabul görmüş olsa da bazı yazarlar, SLN incelemenin sağkalım üzerine yararlı etkisi gösterilemediği için bu yaklaşımı önermemektedir (36). Klinik olarak lenf nodu metastazının beklenmediği $1 \mathrm{~mm}$ altı kalınlığa

\section{Tedavi Yaklaşımları}

sahip evre 0 ve IA MM'de SLN incelemesi önerilmemektedir. Fakat bazı hastane prokollerinde $1 \mathrm{~mm}$ altı kalınlığa sahip olgularda eğer histolojik regresyon, artmış mitoz veya ülserasyon varsa SLN inceleme önerilmektedir (36). SLN metastatik olduğunda terapötik amaçlı bölgesel lenf nodu diseksiyonu yapılır. Yapılacak bölge SLN lokalizasyonuna göre belirlenir. Ayrıca klinik olarak (palpasyon, ultrasonografi [US], bilgisayarlı tomografi [BT] ya da pozitron emisyon tomografisi [PET]) veya histopatolojik olarak (ince iğne aspirasyon biyopsisi) kuvvetle metastaz düşünülen lenf nodları varlığında da selektif lenf nodu diseksiyonu uygulanabilir (36). Bilinen uzak metastaz varlığında, diğer nedenlere bağlı uzun sağkalımın beklenmediği hastalarda ve hastanın genel durumu kötü olup cerrahiye uygun olmadığında ise selektif lenf nodu diseksiyonu rölatif kontraendikedir (36).

Düşük ya da orta riskli MM'li hastalarda (evre IA, IB, IIA) başka tetkike gerek olmasa da bazı hastanelerde evre IB ve IIA MM'de abdominal US istenmektedir. Uzak metastazı düşündüren bulgular varlığında ise $\mathrm{BT}$, magnetik rezonans görüntüleme (MRG) gibi ileri görüntüleme tetkikleri istenmelidir (36).

Yüksek riskli invaziv MM'li olan evre IIB, IIC ve III hastalarda fizik muayene normal olsa bile gizli uzak metastaz riski nedeniyle ileri tetkikler istenmelidir. $\mathrm{Bu}$ hastalarda toraks, abdominal, pelvik BT, kranial MRG/BT, baş-boyun yerleşimli MM'lerde servikal BT ve duruma göre kemik sintigrafisi istenmelidir (36). PET kullanılabilirliği ise tartışmalı bir konudur. Bazı merkezlerde uzak metastazı olan hastalarda, rekürrens şüphesi olanlarda, tedavi uygulanacak metastatik odakların belirlenmesinde ya da diğer metodlar yeterli bilgi vermediğinde kullanılırken bazı merkezler yüksek riskli MM'de ilk evrelendirme değerlendirmelerinde ya da nodal metastazların saptandığ 1 ama orijinin belirlenemediği MM tespitinde PET'in çok yararlı olduğunu vurgulamışlardır (37-39).

AJCC 2009 TNM evreleme sistemine ait kategoriler ve evre grupları Tablo 1 ve 2'de gösterilmiştir.

Primer lokalize kutanöz MM'nin tedavisi geniş eksizyondur. Tanisal biyopsideki Breslow kalınlığına göre belirlenmiş sınırda reeksizyon yapılmaktadır. İn situ tümörlerde $0.5 \mathrm{~cm}$ 
cerrahi sınırla eksizyon yeterli iken $2 \mathrm{~mm}$ ve altı kalınlıktaki lezyonlar için $1 \mathrm{~cm}$ ve $2 \mathrm{~mm}$ üstü kalınlıkta lezyonlar için $2 \mathrm{~cm}$ cerrahi sinırla eksizyon önerilmektedir $(8,36,40)$. Radyoterapi (RT), imiquimod, kriyoterapi gibi tedavi seçenekleri cerrahiyi tolere edemeyecek hastalarda ya da yüzdeki büyük bir lentigo maligna gibi cerrahinin belirgin şekil bozukluğuna yol açacağı hastalarda tercih edilmektedir (36).

Tablo 1: TNM Evrelemesi

\begin{tabular}{|c|c|c|}
\hline Klasifikasyon & Kalınlık (mm) & Ülserasyon/mitoz \\
\hline \multicolumn{3}{|l|}{$\mathbf{T}$} \\
\hline Tis & Uygulanamaz & Uygulanmaz \\
\hline $\mathrm{T} 1$ & $\leq 1.00$ & $\begin{array}{c}\text { a. ülserasyon- ve mitoz }<1 / \mathrm{mm}^{2} \\
\text { b. ülserasyon + veya mitoz } \geq 1 / \mathrm{mm}^{2}\end{array}$ \\
\hline $\mathrm{T} 2$ & $1.01-2.00$ & $\begin{array}{l}\text { a. ülserasyon- } \\
\text { b. ülserasyon+ }\end{array}$ \\
\hline T3 & $2.01-4.00$ & $\begin{array}{l}\text { a. ülserasyon- } \\
\text { b. ülserasyon+ }\end{array}$ \\
\hline $\mathrm{T} 4$ & $>4.00$ & $\begin{array}{l}\text { a. ülserasyon- } \\
\text { b. ülserasyon+ }\end{array}$ \\
\hline Nod & Metastatiknod sayısı & Nodalmetastatik yük \\
\hline N0 & 0 & Uygulanamaz \\
\hline N1 & 1 & $\begin{array}{l}\text { a. mikrometastaz } \\
\text { b. makrometastaz }\end{array}$ \\
\hline N2 & $2-3$ & $\begin{array}{c}\text { a. mikrometastaz } \\
\text { b. makrometastaz } \\
\text { c. intransit/satellit metastaz+, metastatik nod- }\end{array}$ \\
\hline N3 & $\begin{array}{l}\geq 4 \text { metastatik nod veya kümelenn } \\
\text { nod }\end{array}$ & dlar veya intransit/satellit metastaz + metastatik \\
\hline Metastaz & Bölge & Serum LDH \\
\hline M0 & Uzak Metastaz & Uygulanmaz \\
\hline M1a & $\begin{array}{l}\text { Uzak deri, subkutan veya nodal } \\
\text { metastaz }\end{array}$ & Normal \\
\hline M1b & Akciğer metastazı & Normal \\
\hline M1c & $\begin{array}{c}\text { Diğer uzak metastazlar } \\
\text { Herhangi bir uzak metastaz }\end{array}$ & $\begin{array}{l}\text { Normal } \\
\text { Yüksek }\end{array}$ \\
\hline
\end{tabular}

Nodal metastazlarda tedavi lenfadenektomi ve bazı olgularda buna eklenen adjuvan tedavilerden oluşur. Adjuvan tedavi olarak RT veya yüksek doz interferon- $\alpha$ kullanılabilir (36). Metastatik MM'de tedaviler palyatif amaçlıdır. Palyatif tedaviye en uygun adaylar genel sağlik durumu iyi olan ve tümör yükü düşük hastalardır. Tedavi yaklaşımları içinde; metastatik lezyonların cerrahi eksizyonu, paliyatif RT, ekstremite melanomlarında bölgesel sitotoksik ajan perfüzyonu, kemoterapi (dakarbazin, temozalamid, fotemustin, polikemoterapi), immünoterapi (IL-2, GM-CSF, ipilimumab, tremelimumab, inter- 
feron- $\alpha$, aşılar), biyokemoterapi (Kemoterapi+ IL-2/ interferon- $\alpha$ ) ve hedefe yönelik tedaviler
(BRAF inhibitörleri; vemurafenib, dabrafenib, MEK inhbitörü; trametinib) yer alır $(4,8,36)$.

Tablo 2: Klinik ve patolojik evreleme

\begin{tabular}{|c|c|c|c|c|c|c|c|}
\hline \multicolumn{4}{|c|}{ Klinik evre } & & \multicolumn{3}{|c|}{ Patolojik evre } \\
\hline & $\mathrm{T}$ & $\mathrm{N}$ & $\mathrm{M}$ & & $\mathrm{T}$ & $\mathrm{N}$ & $\mathrm{M}$ \\
\hline $\mathbf{0}$ & Tis & No & M0 & $\mathbf{0}$ & Tis & No & M0 \\
\hline IA & T1a & No & M0 & IA & T1a & N0 & M0 \\
\hline \multirow[t]{2}{*}{ IB } & $\mathrm{T} 1 \mathrm{~b}$ & No & M0 & IB & $\mathrm{T} 1 \mathrm{~b}$ & No & M0 \\
\hline & $\mathrm{T} 2 \mathrm{a}$ & No & M0 & & $\mathrm{T} 2 \mathrm{a}$ & No & M0 \\
\hline \multirow[t]{2}{*}{ IIA } & $\mathrm{T} 2 \mathrm{~b}$ & No & M0 & IIA & $\mathrm{T} 2 \mathrm{~b}$ & No & M0 \\
\hline & $\mathrm{T} 3 \mathrm{a}$ & No & M0 & & $\mathrm{T} 3 \mathrm{a}$ & No & M0 \\
\hline \multirow[t]{2}{*}{ IIB } & $\mathrm{T} 3 \mathrm{~b}$ & No & M0 & IIB & $\mathrm{T} 3 \mathrm{~b}$ & No & M0 \\
\hline & $\mathrm{T} 4 \mathrm{a}$ & No & M0 & & $\mathrm{T} 4 \mathrm{a}$ & No & M0 \\
\hline IIC & $\mathrm{T} 4 \mathrm{~b}$ & No & M0 & IIC & $\mathrm{T} 4 \mathrm{~b}$ & No & M0 \\
\hline \multirow[t]{11}{*}{ III } & $\mathrm{T}^{*}$ & $\mathrm{~N}>\mathrm{N} 0$ & M0 & IIIA & $\mathrm{T} 1-4 \mathrm{a}$ & N1a & M0 \\
\hline & & & & & $\mathrm{T} 1-4 \mathrm{a}$ & $\mathrm{N} 2 \mathrm{a}$ & M0 \\
\hline & & & & IIIB & $\mathrm{T} 1-4 \mathrm{~b}$ & N1a & M0 \\
\hline & & & & & $\mathrm{T} 1-4 \mathrm{~b}$ & $\mathrm{~N} 2 \mathrm{a}$ & M0 \\
\hline & & & & & $\mathrm{T} 1-4 \mathrm{a}$ & N1b & M0 \\
\hline & & & & & $\mathrm{T} 1-4 \mathrm{a}$ & $\mathrm{N} 2 \mathrm{~b}$ & M0 \\
\hline & & & & & T1-4a & $\mathrm{N} 2 \mathrm{c}$ & M0 \\
\hline & & & & IIIC & $\mathrm{T} 1-4 \mathrm{~b}$ & N1b & M0 \\
\hline & & & & & $\mathrm{T} 1-4 \mathrm{~b}$ & $\mathrm{~N} 2 \mathrm{~b}$ & M0 \\
\hline & & & & & $\mathrm{T} 1-4 \mathrm{~b}$ & $\mathrm{~N} 2 \mathrm{c}$ & M0 \\
\hline & & & & & $\mathrm{T}^{*}$ & N3 & M0 \\
\hline IV & $\mathrm{T}^{*}$ & $\mathrm{~N}^{*}$ & M1 & IV & $\mathrm{T}^{*}$ & $\mathrm{~N}^{*}$ & M1 \\
\hline
\end{tabular}

\section{Takip}

Kutanöz MM'li hastaların takibinde iki önemli hedef; lokal, bölgesel ya da uzak rekürrenslerin tespiti ve ikincil MM'nin erken tespitidir. Rutin pratikte hastaların hangi tetkiklerle takip edileceğine dair oluşmuş bir konsensus yoktur. Her olgu için klinik ve patolojik evre ve prognostik faktörler belirlenerek ayrı takip prosedürleri oluşturulmalıdır (36).

Her vizitte hastalarda ayrintılı fizik muayene yapılmalı, rekürrense ait bulgu ve semptomlar dikkatlice sorgulanmalidır. Özellikle tüm bölgesel lenf nodlarının detaylı klinik incelenmesi gerekmektedir. Ayrıca hastalara kendilerini muayene etme yöntemleri ve güneşten korunma yolları ayrıntılı olarak öğretilmelidir. Var olan pigmente lezyonlarda

değişiklik, yeni pigmente lezyon ve/veya süperfisyel lenf nodlarında değişiklik fark ettiklerinde uygun merkeze ulaşımları kolaylaştırılmalıdır (36). 
Hayat boyu devam eden ikincil MM riski nedeniyle ailede MM öyküsü ya da klinik olarak atipik nevüsü olan hastalara hayat boyu takip önerilmelidir. Takip süreleri ve gereken tetkikler ile oluşmuş standard konsensus olmamakla birlikte genellikle ilk 3 y1l 3 ayda bir, daha sonra 6-12 ayda bir klinik takip önerilmektedir (40). İn-situ MM'nin klinik takibinde ek görüntüleme veya kan tetkiki gerekmemek-tedir. Bazı merkezlerde düşük/ orta riskli hastalarda (evre IA, IB, IIA) rutin muayene, rutin kan tetkiki, $\mathrm{LDH}$, PAAG ve abdominal USG ile takip (36), yüksek riskli MM'de (evre IIB, IIC, III) ek olarak lenf nodu USG, toraks/abdomen BT, kranial MRI/BT, kemik sintigrafisi ya da tüm vücud PET/PETBT inceleme ile takip önerilmektedir $(36,40)$. Bazı merkezlerde LDH yerine hastalık progresyonu için daha spesifik olan serum S100 seviyesinin takibi yapılmaktadır (40).

\section{Çıkar Çatışması: Yok}

\section{Referanslar}

1. Miller AJ, Mihm MC. Melanoma. N Engl J Med 2006;355:51-65

2. Eggermont AM, Spatz A, Robert C. Cutaneous melanoma Lancet. 2014;383:816-27

3. Bandarchi B, Ma L, Navab R, Seth A, Rasty G. From melanocyte to malignant melanoma. Dermatol Res Pract 2010;2010:583748

4. Tronnier M, Semkova K, Wollina U, Tchernev G. Malignant melanoma: epidemiologic aspects, diagnostic and therapeutic approach. Wien Med Wochenschr 2013;163:354-8

5. Tucker MA. Melanoma epidemiology. Hematol Oncol Clin N Am. 2009;23:383-95

6. Riker AI, Zea N, Trinh T. The epidemiology, prevention, and detection of melanoma. Ochsner $\mathrm{J}$ 2010;10:56-65

7. Psaty EL, Scope A, Halpern AC, Marghoob AA. Defining the patient at high risk for melanoma. Int $\mathrm{J}$ of Dermatol 2010;49:362-76

8. Ingraffea A. Melanoma.Facial Plast Surg Clin North Am 2013;21:33-42

9. Palmieri G, Capone M, Ascierto ML, et al. Main roads to melanoma. J Transl Med 2009;7:86-103

10. Kong Yunyi, Kumar SM, Xu X. Molecular pathogenesis of sporadic melanoma and melanomainitiating cells. Arch Pathol Lab Med 2010;134:1740-9

11. Dankort D, Curley DP, Cartlidge RA, et al. Braf (V600E) cooporates with Pten loss to induce metastatic melanoma. Nat Genet 2009;41:544-52

12. Patton EE, Widlung HR, Kutok JL, et al. BRAF mutations are sufficient to promote nevi formation and cooporate with p53 in the genesis of melanoma. Curr Biol 2005;15:249-54
13. Kraemer KH, Levy DD, Parris CN, et al. Xeroderma pigmentosum and related disorders: examining the linkage between defective DNA repair and cancer. J Invest Dermatol 1994;103:96-101

14. Garibyan L, Fisher DE. How sunlight causes melanoma. Curr Oncol Rep. 2010;12:319-26

15. The international Agency for Research on Cancer Working Group on artificial ultraviolet (UV) light and skin cancer. The association of use of sunbeds with cutaneous malignant melanoma and other skin cancers: a systematic review. Int $\mathrm{J}$ Cancer 2007; 120:1116-22

16. Stern RS, Nichols KT, Vakeva LH. Malignant melanoma in patients treated for psoriasis with methoxsalen (psoralen) and ultraviolet A radiation (PUVA). The PUVA Follow-up Study. N Engl J Med 1997;336:1041-5

17. Stern RS. The risk of melanoma in association with long-term exposure to PUVA. J Am Acad Dermatol 2001;44:755-61

18. Gandini S, Sera F, Cattaruzza MS, et al. Metaanalysis of risk factors for cutaneous melanoma: III. Family history, actinic damage and phenotypic factors. Eur J Cancer 2005;41:2040-59

19. Ferrone CR, Ben Porat L, Panageas KS, et al. Clinicopathological features of and risk factors for multiple primary melanomas. JAMA 2005; 294:1647-54

20. Hemminki K, Zhang H, Czene K. Familial and attributable risks in cutaneous melanoma: effects of proband and age. J Invest Dermatol 2003;120:21723

21. Marghoob AA, Slade J, Salopek TG, Kopf AW, Bart RS, Rigel DS. Basal cell and squamous cell carcinomas are important risk factors for cutaneous malignant melanoma. Screening implications. Cancer 1995;75:707-14

22. Pielop JA, Brownell I, Duvic M. Mycosis fungoides associated with malignant melanoma and dysplastic nevus syndrome. Int J Dermatol 2003;42:116-22

23. Liu W, Dowling JP, Murray WK, McArthur GA, et al. Rate of growth in melanomas: characteristics and associations of rapidly growing melanomas. Arch Dermatol 2006;142:1551-8

24. Chamberlain AJ, Fritschi L, Giles GG, Dowling JP, Kelly JW. Nodular type and older age as the most significant associations of thick melanoma in Victoria, Australia. Arch Dermatol 2002;138:609-14

25. Gandini S, Sera F, Cattaruzza MS, et al. Metaanalysis of risk factors for cutaneous melanoma: I. Common and atypical naevi. Eur $\mathrm{J}$ Cancer 2005;41:28-44

26. McKenna DB, Stockton D, Brewster DH, Doherty VR. Evidence for an association between cutaneous malignant melanoma and lymphoid malignancy: a population-based retrospective cohort study in Scotland. Br J Cancer 2003;88:74-8

27. Brennan $\mathrm{P}$, Coates $\mathrm{M}$, Armstrong $\mathrm{B}$, Colin $\mathrm{D}$, Boffetta P. Second primary neoplasms following non-Hodgkin's lymphoma in New South Wales, Australia. Br J Cancer 2000;82:1344-7

28. Levi F, Randimbison L, Te VC, La Vecchia C. NonHodgkin's lymphomas, chronic lymphocytic leukemias and skin cancers. $\mathrm{Br} \mathrm{J}$ Cancer 1996;74:1847-50 
29. Jensen P, Hansen S, Møller B, et al. Skin cancer in kidney and heart transplant recipients and different long-term immunosupressive therapy regimens. J Am Acad Dermatol 1999;40:177-86

30. Euvrard S, Kanitakis J, Claudy A. Skin cancers after organ transplantation. N Engl J Med 2003;348:168191

31. Yuvale FO, Halpern AC. Melanoma. In: Bolognia JL, Jorizzo JL, Rapini RP, eds. Dermatology (2nd ed). Spain; Mosby Elsevier;2008:1745-69

32. McKee PH, Calonje E. Melanocytic Pathology (3rd ed). China;Mosby Elsevier; 2009

33. Elder DE, Elenitsas R, Murphy GF. Benign pigmented lesions and malignant melanoma. In: Elder DE, Elenitsas R, Johnson BL, Murphy GF, Xu $\mathrm{X}$, eds. Histopathology of the skin (10th ed). Philadelphia; Lippincott Williams \& Wilkins;2009:699-789

34. Frishberg DP, Balch C, Balzer BL, et al. Protocol for the examination of specimens from patients with melanoma of the skin. Arch Pathol Lab Med 2009;133:1560-7

35. Schuchter L, Schultz DJ, Synyuvavedt M, et al. Aprognostic model for predicting 10-year survival in patients with primary melanoma. Ann Intern Med 1996; $125: 369-75$
36. Mangas $\mathrm{C}$, Paradelo $\mathrm{C}$, Puig $\mathrm{S}$, et al. Initial evaluation, diagnosis, staging, treatment, and follow-up of patients with primary cutaneous malignant melanoma. Consensus statement of the Network of Catalan and Balearic Melanoma Centers. Actas Dermosifiliogr 2010;101:129-42

37. Maubec E, Lumbroso J, Mason F, et al. F-18 fluorodeoxy-D-glucose positron emission tomography scan in the initial evaluation of patients with a primary melanoma thicker than $4 \mathrm{~mm}$. Melanoma Res 2007; 17:147-54

38. Brady MS, Akhurst T, Spanknebel K, et al. Utility of preoperative 18F-fluorodeoxyglucose-positron emission tomography scanning in high-risk melanoma patients. Ann Surg Oncol 2006;13:525-32

39. Prichard RS, Hill AD, Skehan SJ, O'Higgins NJ. Positron emission tomography for staging and management of malignant melanoma. $\mathrm{Br} \mathrm{J}$ Surg 2002;89:389-96

40. Dummer R, Hauschild A, Guggenheim M, Keilholz U, Pentheroudakis G; ESMO Guidelines Working Group. Cutaneous melanoma: ESMO Clinical Practice Guidelines for diagnosis, treatment and follow-up.Ann Oncol 2012;23:vii86-vii91 